\title{
Recovery of function from septal damage and the growth of sympathohippocampal fibers
}

\author{
M. D. CHAFETZ, S. EVANS, and F. H. GAGE \\ Texas Christian University, Fort Worth, Texas
}

\begin{abstract}
After septohippocampal damage in the rat, a growth of fibers of sympathetic origin is observed in the hippocampus. The time course of this growth parallels the changes in behavior seen after septal lesions. This study determined quantitatively which pattern of behavioral changes was most closely associated with the growth of sympathetic fibers. We found two patterns of behavioral change associated with the growing fibers. One pattern was of "recovery" behaviors, whereas the other was of "deficit" behaviors. The recovery behaviors included tactile reactivity and open-field activity. The deficit behaviors included shock and heat reactivity. In addition, we argue that the fluorescence intensity measure of sympathetic fibers that relates to neurotransmitter content is most appropriate to use in future studies of behavior, because this measure was consistently well correlated with behavioral changes.
\end{abstract}

Following septohippocampal damage to the fornix (Loy, Milner, \& Moore, 1980; Loy \& Moore, 1977; Milner \& Loy, 1980; Stenevi \& Bjorklund, 1978), anterodorsal hippocampus (Kimble, Anderson, BreMiller, \& Dannon, 1979; Kimble, BreMiller, \& Perez-Polo, 1979; Loy \& Moore, 1977), or medialseptal/diagonal-band nuclei (Crutcher, Brothers, \& Davis, 1981; Crutcher \& Davis, 1981b), the hippocampus experiences a growth of sympathetic, noradrenergic fibers whose cell bodies of origin reside in the superior cervical ganglia (SCG). These sympathetic fibers appear to extend from their normal termination in blood vessels (Loy \& Moore, 1977; Milner \& Loy, 1980) into areas of hippocampal parenchyma denervated of cholinergic septal afferents (Crutcher et al., 1981; Crutcher \& Davis, 1981a, 1981b). This growth takes longer than lesion-induced growth in central hippocampal afferents (Milner \& Loy, 1980). The final distribution of sympathohippocampal sprouts appears similar to that when SCG are transplanted into the fornix or anterior hippocampus of sympathectomized rats (Bjorklund \& Stenevi, 1977; Stenevi, Bjorklund, \& Svendgaard, 1976). The growth of these fibers may be triggered by more than one trophic factor (Crutcher \& Collins, 1982) released by the hippocampus after cholinergic deafferentation (Crutcher et al., 1981).

If these sympathohippocampal sprouts release their contents functionally into the hippocampus, the potential for behavioral change is great. For ex-

This research was part of a doctoral dissertation by the first author performed in the laboratory of F. H. Gage at Texas Christian University. Requests for reprints should be addressed to Michael D. Chafetz, Department of Psychology, P.O. Box 43131, University of Southwestern Louisiana, Lafayette, Louisiana 70504. ample, sympathetic neurons contain norepinephrine (Morgan \& Hansen, 1978), and sympathohippocampal sprouts are identifiable on the basis of norepinephrine made fluorescent by histochemistry (Loy \& Moore, 1977; Stenevi \& Bjorklund, 1978). When exogenous norepinephrine is injected directly into the hippocampus, animals will exhibit a number of behavioral changes, including open-field activity and shock reactivity (Gage \& Springer, 1981). Similarly, sympathetic neurons contain polypeptides with opiatelike immunoreactivity (DiGiulio, Yang, Lutold, Fratta, Hong, \& Costa, 1978), and intrahippocampal injections of morphine will alter the same behaviors, albeit in a different direction (Valdes, Cameron, Evans, \& Gage, 1980).

If the damage that elicited sympathohippocampal sprouting first resulted in behavioral changes, then subsequent changes induced by the slowly growing sympathohippocampal sprouts become important. There are primarily two areas of importance. First, recovery of function may occur, possibly by the reestablishment of a noradrenergic mileau in hippocampus (Gage \& Olton, 1976; Gage \& Springer, 1981; Gage, Thompson, \& Valdes, 1978). Increased opiate activity may also play a part in lessening the hyperreactivity observed after septal lesions (DiGiulio et al., 1978; Valdes et al., 1980). Second, the establishment of deficit may occur by virtue of the newly developed connections between two systems that were not previously connected (Schneider, 1973). If there were previous connections (Wall \& Egger, 1971), then this would imply the establishment of function in connections that were previously silent (unmasking). The two major possibilities (recovery and deficit) are separable only by studies of the behavioral significance of sympathohippocampal sprouting. 
In the first set of such studies, the authors concluded that there was no behavioral significance of this sprouting. Locomotor activity, spontaneous alternation, and spatial maze learning were not significantly affected as a result of ganglionectomy following anterodorsal hippocampal lesions, Kimble, Anderson et al., 1979). When nerve growth factor was injected in an attempt to increase sympathetic growth, these behaviors were also unaffected (Kimble, BreMiller, \& Perez-Polo, 1979). Gage and his coworkers (Moes, Graves, Kesslak, \& Gage, 1981), however, have reported that ganglion removal accentuated the reactivity differences that were apparent between animals tested in light or dark conditions after septal lesions.

The present study takes advantage of the similar time course between changes in reactivity following septal lesions (Brady \& Nauta, 1955; Gage et al., 1978) and the growth of sympathohippocampal sprouts (Milner \& Loy, 1980) to identify the behaviors most closely associated with this sprouting. Time was used as an independent variable to manipulate both behavioral and neural changes after septal lesions. Specifically, we sought to delineate the classes of behaviors that change following septal lesions and to identify which of these classes is most closely associated with sympathetic growth. To identify these classes, canonical-correlations analysis was used as a method for describing the best linear combination of two sets of variables: behavioral and neural. The measurement of sympathetic growth has been described previously (Chafetz, Evans, \& Gage, 1982; Chafetz \& Gage, 1982).

\section{METHOD}

This study reports the behavioral outcomes of the project (Chafetz, 1981) in which recovery of function and sympathetic ingrowth were described. The measurement technique (Chafetz \& Gage, 1982) and the subsequent measurement of sympathohippocampal growth (Chafetz et al., 1982) have been reported previously. The experimental design and other methods have therefore also been reported, but the particulars will be repeated here.

\section{Animals}

Eighty-six female Sprague-Dawley rats weighing 200-350 g at the time of surgery were housed individually in a temperaturecontrolled $\left(21^{\circ} \mathrm{C}\right)$ vivarium. Twenty of these animals were included as extras to substitute for those animals unable to complete the study. Females were used because the postlesion growth of sympathetic fibers may be greater in females (Loy \& Milner, 1980). The animals were maintained on a 12-h:12-h reversedlighting cycle, lights off at $0800 \mathrm{~h}$. They had ad-lib access to lab chow and water.

\section{Surgery}

The animals were injected with $.5 \mathrm{mg} / \mathrm{kg}$ of atropine sulfate (Atrosol) $10 \mathrm{~min}$ prior to receiving an anesthetic dose of ketamine chloral hydrate $(30 \mathrm{mg} / \mathrm{kg}$ of ketamine; $120 \mathrm{mg} / \mathrm{kg}$ of chloral hydrate). Each animal was positioned in a stereotaxic instrument, with the upper incisor bar $5 \mathrm{~mm}$ above the interaural line. Standard surgical procedures were followed to expose the skull. The stereotaxic coordinates for animals receiving septal (SEPX) and sham (SHAM) lesions were: A, +1.8; L, +.5; $\mathrm{V}$, -4.8. Lesions were made in SEPX animals by passing a 13-mA rf current for 14-sec through a No. 2 insect pin insulated, except for $.5 \mathrm{~mm}$ at the tip, with INSL-X. The insect pin was inserted to the same position in SHAM animals, but current was not passed.

\section{Fluorescence Histochemistry and Measurement}

A modification of de la Torre and Surgeon's (1976) glyoxylic acid dip method was used. Fluorescent areal density and fiber intensity were measured using the microfluorometric (MF) method described previously (Chafetz \& Gage, 1982). The data on sympathetic ingrowth have been reported previously (Chafetz et al., 1982), but are used here to identify the behaviors most closely associated in time with sympathetic ingrowth. The data presented in this paper also include measurements of pineal and habenula (Chafetz \& Gage, in press). These data have no bearing on the present results, but are included because they were necessary to derive the correct weights in the original multivariate analyses (Chafetz, 1981). As described, the MF method yields two independent measures of the field of fluorescence. Density refers to an areal density of fibers as would be measured by using stereological methods on micrographs. Intensity refers to the mean fluorescence intensity of measured fibers. The MF method yields original data expressed in percentages for areal density and in arbitrary fluorescence units for fiber intensity.

As described in Chafetz et al. (1982), the measurement areas are as follows: (A) hippocampus-(1) dorsal dentate hilus, (2) dorsal CA3, (3) posterior dorsal dentate hilus, (4) posterior ventral hilus, (5) posterior ventral subiculum; (B) pineal gland; (C) habenula. The density and intensity measures were obtained in each of these areas except the habenula, where it was not possible to measure density.

\section{Behavioral Testing}

For tactile reactivity, a modification of a previously used rating scale (Chafetz, Thompson, Evans, \& Gage, 1981) was used. The animals were rated on their responses to four stimuli: a puff of air to the back, a light tap to the snout with a glass rod, a light tap to the flank with a glass rod, and handling. For each stimulus, a 7-point rating scale was used, with 0 indicating the absence of responding and 6 indicating the largest magnitude of response. With this scale, anesthetized animals receive a total rating of 0 , while untreated rats typically receive a score of 12. The highest possible rating is 24 . This rating scale has an interrater reliability of $r>.9$ (Chafetz, 1981).

Responsiveness to heat was measured with the hot plate set at $52^{\circ} \mathrm{C}$ (Antier, 1974). The latency in seconds for the animal to lick a hind paw was recorded, and the animal was then removed. The ceiling for this response was set at $60 \mathrm{sec}$.

Special apparatus has been constructed to measure an animal's response to shock (Gage, Armstrong, \& Thompson, 1980; Turner \& Gage, in press). The animal was shocked five times with a .5-mA current at a variable interval mean of $30 \mathrm{sec}$. The current chosen was the level that produced half maximal response in normal, untreated animals (Gage et al., 1980). Response amplitude was integrated over time and was termed the "integral" (INT) of response to shock. The average integral was obtained by dividing INT by duration (DUR). Response latency (LAT) was also obtained.

Electrical activity of the superior cervical ganglion has been associated with the orienting reflex, food seeking, sniffing, drinking, and the transition from waking to sleep (Nikolov, 1976). Open-field behaviors are altered by septal lesions (Gage et al., 1978) and were therefore included in the testing battery. The individual behaviors were: latency to cross from the center to the 
periphery of the open field (OLAT), and locomotor activity (LINS) and rearing (RRS) in the open field. The open field was a black-painted activity box $(117 \times 117 \times 50 \mathrm{~cm})$ marked into 16 squares with white lines. It was illuminated from above with a 15-watt red bulb. The animal was removed from its home cage and lowered through a black-painted tunnel into the center of the open field. The tunnel was removed, and OLAT was recorded (ceiling $=60 \mathrm{sec}$ ). The animal was then permitted to explore the open field for 2 min, during which LINS and RRS were tabulated.

\section{Experimental Design and Preliminary Analyses}

There were 20 postlesion times of measurement, one on each odd-numbered day from Day 1 to Day 39. Three animals were assigned randomly to each testing day, and the order of testing days was also randomized. On each testing day, the animal's behavior was recorded, and the animals were then killed for fluorescence histochemistry. Both the behavioral scores and the fluorescence measurements on each test day were therefore independent of the scores on every other test day. The test day was the unit of analysis, and the mean of the three animals' scores on each variable was analyzed as the test day's score on that variable. One might think of this design as a dose-response paradigm, with different dosages of growth being administered to each test day's group of animals. Correlations between behaviors and neural measurements therefore represent the effects of time over a fairly wide range of measurement (40 days). Individual animal scores were excluded from the analysis on the day's score by corroborating Q-factor principal-component results with measurement-day notes (Chafetz, 1981), leaving scores from 55 animals to represent 20 days of measurement. The Q-factor analysis derives from the correlation of each animal's scores with the best linear combination of the measurement-day scores (Nie, Hull, Jenkins, Steinbrenner, \& Bent, 1975) and is therefore ideally suited to the identification of the animal's scores not represented (correlated) on the measurement day. For example, if we observed that an animal was sick on a particular measurement day, its scores were not discarded unless those scores also did not correlate .75 with the linear combination best representing the entire measurement day.

There are several possible classes of change that behavior could undergo after lesions. Deficit and recovery are only two possible directions, and within each direction there are several possible paths, including linear and curvilinear changes. The analytical technique that best describes these classes is principalcomponents analysis, because it derives the linear combination that best correlates with the behavioral variables (Evans, Neideffer, \& Gage, 1981). The behaviors that show the highest intercorrelations define the first component. Succeeding components are derived from the residuals after the preceding component is defined so that each component is independent of the rest. In this way, principal-components analysis accounts for groups, or classes, of intercorrelations.

The second objective was to identify which behavioral changes were most closely associated in time with sympathetic ingrowth. Because it would be most interesting to identify classes of behavioral changes associated with classes of neural changes, a technique related to principal-components analysis was used. Canonical-correlations analysis derives the linear combinations that best correlate with variables from two separate sets (Levine, 1977). In this case, one set consisted of behavioral variables, whereas the second set consisted of fluorescence variables analyzed previously (Chafetz et al., 1982). The canonical-analysis facilitates the identification of those variables (behavioral and neural) belonging to a class of changes by weighting the variables with the highest intercorrelations most highly. The results are then interpretable in light of the pattern of intercorrelations between behavioral and neural variables. Because succeeding canonical variates are derived from the residuals after the preceding variate is defined, each canonical variate is independent of the rest. As with principal-components analysis, the canonical analysis therefore accounts for groups, or classes, of correlations.

\section{RESULTS}

The principal-components analysis of postlesion scores (Table 1) revealed that the first component accounted for $47 \%$ of the variance in the behavioral scores. The variables sharing at least half their variance $(r>.7)$ with the component were: INT, response to tactile stimuli (RSCL), OLAT, LAT, and LINS. Considering the sign of the correlations, an animal with a high component score exhibited: a strong response to shock, a strong reaction to tactile stimuli, a long latency to traverse to the perimeter of the open field, a quick response to shock, and few lines crossed in the open field.

These behaviors were then combined into one aggregate (P1) on the basis of their correlations with the first component. Table 2 shows the correlation matrix including time as a variable along with the aggregate of behavior. P1 correlates significantly in a negative direction with time $(r=-.54, p<.05)$, indicating that these behaviors changed over time toward prelesion baseline. The individual behaviors most correlated with time were: RSCL $(r=-.63, p<$ $.05)$ and LINS $(r=-.60, p<.05)$. Figures 1 and 2 depict these changes over time.

Although not an objective of this study, it was also interesting to identify the variables that remained relatively unchanged following septal lesions. If preoperation and postoperation scores are considered in separate groups, then change over time represents error variance in the postoperative group of scores. The behaviors that change because of the lesion and then remain at the new level over time would have a mean in the postoperative scores different from that in the preoperative scores, with

Table 1

Principal Components Analysis of Postop Behavior

\begin{tabular}{lrrr}
\hline & p1 & p2 & pvar \\
\hline INT & .86 & .45 & .95 \\
RSCL & .83 & & .71 \\
OLAT & .71 & & .55 \\
DUR & .60 & .69 & .83 \\
I/D & .56 & & .32 \\
RRS & -.55 & .61 & .67 \\
PLK & -.58 & .43 & .52 \\
LAT & -.70 & -.60 & .84 \\
LINS & -.74 & .42 & .73 \\
PVAR & .47 & .20 & \\
CPV & .47 & .68 & \\
\hline
\end{tabular}

Note $-P L K=$ pawlick latency; $R S C L=$ rating scale; $O L A T=$ latency (open field); RRS = rearings frequency; LINS = lines crossed (open field); INT = integral (shock explained in text); $D U R=$ duration, shock response; $L A T=$ latency, shock response $; I / D=$ average integral; $P V A R=$ proportion of variance; $C P V=$ cumulative proportion of variance. 
Table 2

Correlation Matrix of Postop Behavior Including Time and the Behavioral Aggregate (P1) as Variables

\begin{tabular}{lrrrrrrrrr}
\hline & TM & \multicolumn{1}{c}{ P1 } & PLK & RSCL & LTCY & RRS & LINS & INT & DUR \\
\hline P1 & -.54 & & & & & & & & \\
PLK & .43 & -.58 & & & & & & & \\
RSCL & -.63 & .85 & -.45 & & & & & & \\
LTCY & & .71 & -.43 & .62 & & & & & \\
RRS & & -.51 & .39 & -.48 & -.43 & & & \\
LINS & .60 & -.75 & .55 & -.67 & -.50 & .65 & & & \\
INT & -.38 & .85 & -.30 & .60 & .44 & -.25 & -.43 & & \\
DUR & -.25 & .60 & & .37 & .29 & & -.26 & .82 & -.73 \\
LAT & & -.69 & & -.46 & -.31 & & & \\
I/D & & .54 & -.31 & .35 & .31 & -.31 & .30 & .55 & \\
\hline
\end{tabular}

Note-LTCY = latency; other abbreviations are given in Table 1 and in text. Correlations less than .24 have been blanked out for clarity.

little error variance (change over time). A discriminant-function analysis identifies the variables accounting for the greatest amount of between-groups variance, relative to error variance. This analysis was therefore used to identify the behaviors most consistently changed by the operation. (A preliminary regression analysis revealed that very little variance in the postoperative scores was accounted for by individual differences, so that pre- and postoperative scores could be considered as separate groups.)

The results of this analysis are shown in Table 3. The first discriminant function accounted for $83 \%$ of the between-groups differences $\left(\chi^{2}=59, \mathrm{p}<.01\right)$. The variables showing the most consistent change following the operation were RRS and INT (shock response). The signs of the discriminant weights indicated that shock response was elevated after the lesion, and it remained elevated (with minor changes over time) during the course of the study. The correlation of INT and RSCL gave INT its correlation on the behavioral aggregate and indicates that INT's correlation on $\mathrm{P} 1$ is spurious.

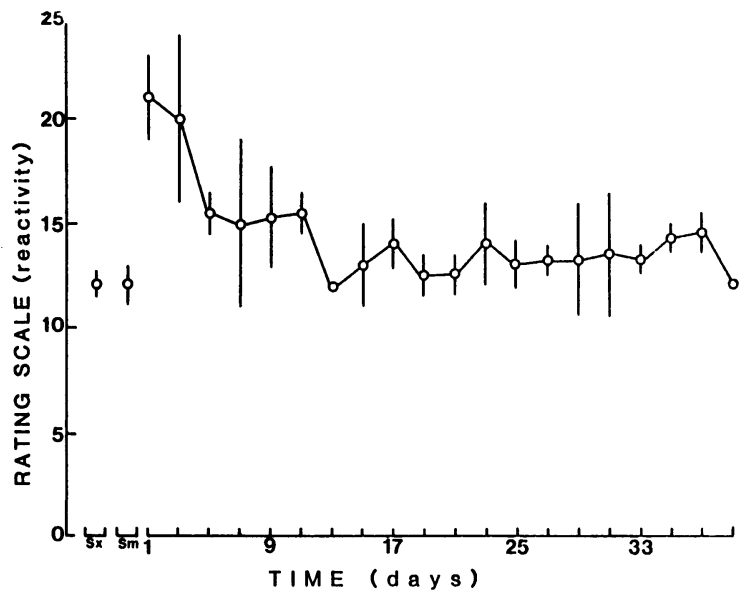

Figure 1. Plot reactivity (rating scale score) over time, showing means and $95 \%$ confidence intervals at each time period $(\mathrm{Sm}=$ sham; Sx = superior cervical ganglionectomy).
Canonical analysis was then performed on the behavioral and neural variables. The first canonical analysis was performed as an act of data reduction for the following reason. It was not possible to obtain measurements in pineal on all 20 days of measurement (Chafetz \& Gage, 1982). The reduced $\mathbf{n}$ necessitated the reduction of the overall number of variables so that the most interesting ones could be included in the final analysis. Because canonical analysis identifies the most important (highest correlated) variables, it was used first to reduce the data set to these variables. The pineal variables were excluded from the first data-reduction analysis. Table 4 gives, for this first analysis, the individual correlations with the canonical variate. The first canonical variate accounts for $79 \%$ of the variance between the two composite scores. The individual correlations show that subiculum intensity (SUI) and habenula intensity (HAB) contribute most to the neural composite, while DUR, average shock response (I/D), and $\mathrm{P} 1$ contribute most to the behavioral composite. The second canonical variate, of less importance than the first, indicated that SUI,

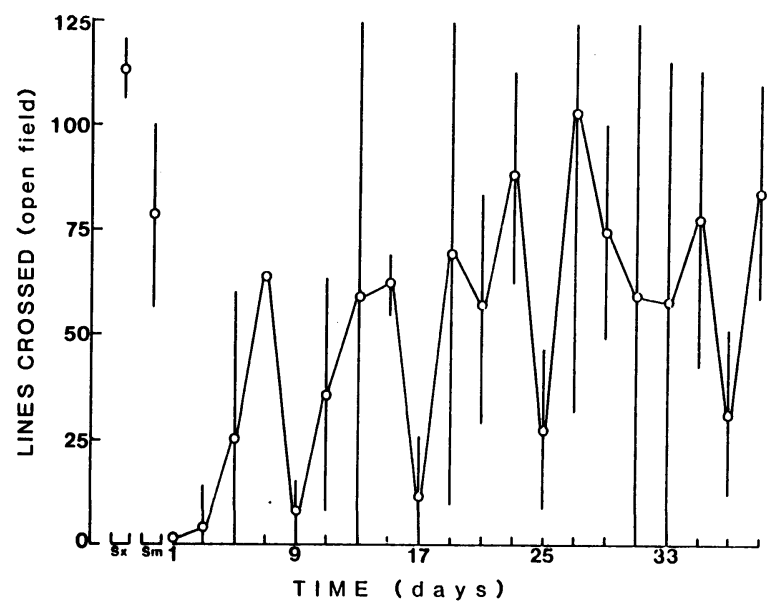

Figure 2. Plot of lines crossed in the open field, showing means and $95 \%$ confidence intervals at each time period (Sm = sham; Sx = superior cervical ganglionectomy). 
hippocampus intensity (HPI), RRS, DUR, and I/D were also interrelated. The signs of the correlations indicate the relative direction of the interrelationships. Because it was of interest to include pineal changes in the analysis (Chafetz, 1981; Chafetz \& Gage, in press), the reduced variables were selected for a final canonical analysis.

The scores from testing days on which there were no pineal measurements (Days 1,5 , and 31) were removed from the data matrix, leaving $n=17$. Pineal intensity (PII) and density (PID) were then included among SUI, HAB, and HPI as neural variables. The behavioral variables were RRS, DUR, I/D, and $P 1$. The analysis on this reduced matrix is presented in Table 5.

Table 3

Discrimination Between Preop and Postop Behavior

\begin{tabular}{lrr} 
& \multicolumn{2}{c}{$\mathrm{d} 1$} \\
\cline { 2 - 3 } & $\mathrm{pvc}$ & \multicolumn{1}{c}{ wts } \\
\hline RRS & .46 & 2.02 \\
INT & .42 & -1.95 \\
I/D & .04 & .58 \\
LAT & .04 & .56 \\
RSCL & .02 & .42 \\
LINS & .02 & .38 \\
DUR & .01 & .26 \\
PLK & & .20 \\
LTCY & & .15 \\
PVR & .83 & \\
DISCRIT & 4.81 & \\
\hline
\end{tabular}

Note-Abbreviations are given in Table 1. Additionally, $d 1=$ first discriminant function; $L T C Y=$ latency; $P V R-B G=$ proportion of variance between groups; DISCRIT = discriminant criterion.

Table 4

First Canonical Correlations Analysis to Reduce Variable Sets $(n=20)$

\begin{tabular}{|c|c|c|c|c|}
\hline Canon & $\begin{array}{l}\text { Variates } \\
\text { Canon } \mathrm{r} \\
\end{array}$ & $\begin{array}{l}\mathrm{c1} \\
.89 \\
\end{array}$ & $\begin{array}{l}\mathrm{c} 2 \\
.78 \\
\end{array}$ & $\begin{array}{r}c 3 \\
.67 \\
\end{array}$ \\
\hline \multicolumn{5}{|c|}{ Correlations With Original Variables } \\
\hline $\mathbf{N}$ & PDD & -.06 & -.07 & .02 \\
\hline $\mathrm{N}$ & PVD & .26 & -.07 & -.11 \\
\hline $\mathbf{N}$ & SUI & -.53 & .69 & .37 \\
\hline $\mathbf{N}$ & SUD & -.06 & -.11 & -.83 \\
\hline $\mathbf{N}$ & DHD & -.06 & -.16 & .44 \\
\hline $\mathrm{N}$ & CAD & -.31 & -.27 & .34 \\
\hline $\mathbf{N}$ & HAB & -.59 & -.39 & .25 \\
\hline $\mathbf{N}$ & HPI & .03 & .54 & .62 \\
\hline B & PLK & -.01 & -.24 & -.32 \\
\hline B & RRS & .02 & -.54 & -.40 \\
\hline B & DUR & .58 & .67 & -.22 \\
\hline B & $\mathrm{I} / \mathrm{D}$ & -.45 & .48 & .69 \\
\hline B & P1 & .43 & .66 & .55 \\
\hline
\end{tabular}

Note $-N=$ neural variables; $B=$ behavioral variables; $P D D=$ posterior dorsal density; $P V D=$ posterior ventral density $=S U I=$ subiculum intensity; $S U D=$ subiculum density; $D H D=$ dorsal hilus density; $C A D=C A 3$ density; $H A B=$ habenula density; $H P I=$ hippocampus intensity; $P L K=$ pawlick latency; $R R S=$ rearing; $D U R=$ duration of shock response; $I / D=$ average shock response; $P 1=$ behavioral aggregate; The neural variables have been described in Chafetz et al. (1982).
Table 5

Canonical Correlations Analysis on Reduced Set of Variables (Includes Pineal, $\mathbf{n}=17$ )

\begin{tabular}{|c|c|c|c|c|}
\hline Canon & $\begin{array}{l}\text { Variates } \\
\text { Canon } r \\
\text { Variance } r^{2}\end{array}$ & $\begin{array}{l}\mathrm{c} 1 \\
.88 \\
.77\end{array}$ & $\begin{array}{l}\mathrm{c} 2 \\
.79 \\
.62\end{array}$ & $\begin{array}{l}c 3 \\
.66 \\
.44\end{array}$ \\
\hline \multicolumn{5}{|c|}{ Correlations With Original Variables } \\
\hline $\mathrm{N}$ & PII & -.31 & .64 & -.53 \\
\hline $\mathbf{N}$ & PID & -.25 & -.02 & .16 \\
\hline $\mathbf{N}$ & SUI & -.76 & .50 & -.12 \\
\hline $\mathbf{N}$ & $\mathrm{HAB}$ & -.31 & -.48 & -.64 \\
\hline $\mathrm{N}$ & HPI & -.36 & .74 & -.28 \\
\hline B & RRS & .42 & -.60 & -.16 \\
\hline B & DUR & .08 & .57 & .56 \\
\hline B & $\mathrm{I} / \mathrm{D}$ & -.77 & .38 & -.43 \\
\hline B & P1 & -.16 & .98 & -.04 \\
\hline
\end{tabular}

Note-Abbreviations are given in Tables 1 and 4.

Table 6

Correlation Matrix of Neural and Behavioral Variables

\begin{tabular}{lrrrrrrr}
\hline & RRS & DUR & I/D & P1 & PII & PID & SUI \\
\hline I/D & -.30 & & & & & & \\
P1 & -.56 & .60 & .55 & & & & \\
PII & -.32 & & .57 & .56 & & & \\
PID & & & & & & & \\
SUI & -.50 & & .70 & .50 & .61 & & \\
HAB & & -.49 & .25 & -.31 & & .32 & \\
HPI & -.48 & & .53 & .62 & .60 & & .53 \\
\hline
\end{tabular}

Note $-R R S=$ rearing; $D U R=$ duration shock response $; I D=$ average shock response; $P 1$ = aggregate behavioral scores; $P I I=$ pineal intensity; $P I D=$ pineal density; $S U I$ = subiculum intensity; $H A B=$ habenula (intensity); HPI = hippocampus intensity (aggregate).

Table 5 shows that the first canonical variate accounted for $77 \%$ of the variance between the neural and behavioral composites. This indicates a high degree of intercorrelations between behavioral and neural variables. The variables with the highest correlations with this canonical variate were SUI and I/D, each with the same sign of correlation. The strong individual correlation between SUI and I/D (Table 6) was the principal reason for the high weights here. The correlations with the second canonical variate showed that PII, SUI, and HPI were strongly related to $P 1$, all with the same sign of correlation. Therefore, a second dimension of relatedness between behavioral and neural variables was shown by these high weights. The individual correlations are shown in Table 6.

\section{DISCUSSION}

The notion of "syndrome" implies a constellation, or class, of symptoms in each individual. The septal syndrome has been discussed by several investigators as being composed of "hyperreactivity" (Gage \& Olton, 1975; Gage et al., 1978), "hyperemotionality" (Brady \& Nauta, 1955; Donovick \& Wakeman, 
1969), "hypoactivity" (Gage et al., 1978; Kohler \& Srebro, 1980) or "hyperactivity" (Gay, 1977; Kohler \& Srebro, 1980), and "hyperalgesia" (Valdes et al., 1980). These constructs are marshalled by an a priori focus on the particular behaviors of interest to the investigator. In contrast, the present study empirically identifies classes of behavior on the basis of intercorrelations between behaviors changed as a result of septal lesions. Specifically, we identified two classes of behavior changed as a result of septal lesions: (1) behaviors that change further in the direction of predamage baseline; and (2) behaviors that remain unchanged by the lesion for long periods of time. The first class could be seen as "recovery" behaviors, whereas the second class could be identified as "deficit" behaviors.

The importance of identifying these two classes lies primarily in their implication for neural mechanisms. Behaviors that recover following a lesion indicate a neural reorganization in a site (or sites) distal, but functionally connected, to the damaged area (Schoenfeld \& Hamilton, 1977). In contrast, behaviors that remain changed after a lesion indicate that the damaged site itself was critical in processing some aspect of these behaviors; at least, no amount of reorganization in other functionally connected areas aided in the recovery of these behaviors. In the latter case, it is important that implantation of fetal tissues cannot only restore the correct connections from a damaged site (Bjorklund, Segal, \& Stenevi, 1979; Kromer, Bjorklund, \& Stenevi, 1980), but that behavior can change as a functional result of this restoration (Bjorklund, Dunnett, Stenevi, \& Gage, 1982).

In previous studies, fluorometric techniques were developed (Chafetz \& Gage, 1982) to measure the density and intensity of neural sprouts after septal lesions (Chafetz et al., 1982). The present study identified how these measures were associated with behavioral changes following septal lesions. The strongest linear correlations were identified between behavioral variables and fluorescence intensity variables, especially between an average shock response and subiculum intensity. The subiculum was where the growth of sympathohippocampal sprouts could best be measured (Chafetz et al., 1982), so the finding of such a strong correlation with behavior here was especially important. The subiculum in primates is the major source of hippocampal efferents to medial frontal cortex, caudal cingulate gyrus, and amygdala (Rosene \& Van Hoesen, 1977). If the growth of these fibers provides a functional input to subiculum, a widespread effect via subiculum efferents is possible.

As we (Chafetz \& Gage, 1982) and others (Geyer, Dawsey, \& Mandel, 1978) have discussed, fluorescence intensity probably indicates the relative level of neurotransmitter in the fibers that were measured. Density, in comparison, merely reflects the percentage surface area covered by fluorescent fibers. These interpretations suggest that behavior is associated with neural processes (uptake, release, synthesis) that lead to changes in neurotransmitter content, thus affecting fiber intensity, not density, and hence, function, not structure. This suggestion of course implies that the growing sympathohippocampal sprouts are functional. To this end, it is important to note again that intrahippocampal injections or norepinephrine resulted in increases in activity and reactivity in normal animals (Gage \& Springer, 1981). These behaviors were the same ones seen to change as a result of septal lesions in the present study. Similar quantitative, "within-animal" relationships have been reported in other laboratories. Jones, Foote, Segal, and Bloom (1978) have reported an increased firing of locus coeruleus cells in the freely moving rat in response to various external stimuli. The firing rate decreases as the animal's state of arousal progresses from wakefulness through slow-wave sleep into paradoxical sleep. These several results converge on the conclusion that activity of norepinephrine-containing cells is associated with and perhaps necessary for behavioral activity and reactivity, and that the present return to normal activity levels may have been associated with the growth of sympathetic, noradrenergic fibers.

The independence of the measures of fluorescent fibers (Chafetz \& Gage, 1982) suggests that our present findings may be generalized. The measure of density may reveal changes in structure (placement, distribution, and number of connections), but may not necessarily be associated with functional, behavioral changes. The possibility of "silent synapses" (Wall \& Egger, 1971) makes this clear. Density, however, could relate to a functional change if a denser growth were able to deliver more neurotransmitter to a given area. An example of this possibility may be seen in a measurement of habenular innervation after septal damage (Chafetz \& Gage, in press) in which the growth is so dense that a change in intensity is measured as well.

The canonical-correlations analysis indicated that the second strongest set of correlations between behavioral and neural changes (second canonical variate) occurred between two intensity variables (hippocampus and pineal) and the behavioral aggregate (P1). This again lends support to the notion that behavior is associated with a fluorescence measure that relates to neurotransmitter content in the fibers measured. Because the sympathetic nervous system has a number of termination sites within the central nervous system, changes in sympathetic innervation in these sites may be the "physiological tip of the 
iceberg," as we have discussed (Chafetz \& Gage, in press). Sympathetic regulation throughout the entire body may be substantially altered by the septal lesion, so it is important here that the strong correlations occurred between the neural changes and the aggregate of several intercorrelated behaviors.

In summary, we have identified two classes of behaviors that change as a result of septal lesions, each associated with different aspects of sympathohippocampal fiber growth. One class of "deficit" behaviors changes after the lesion and then remains relatively invariant over time. The other class of "recovery" behaviors changes as a result of the lesion and then changes again over time in the direction of predamage baseline. We have discussed these concepts in previous studies (Gage et al., 1980; Gage et al., 1978; Valdes et al., 1980). We have also shown how measurements of sympathetic ingrowth were associated with an aggregate of "recovery" behaviors, and how a nonrecovery behavior (response to shock) was associated with one measure of fiber growth. Although not conclusive, this finding was quite suggestive of the behavioral effect of the ingrowing fibers, especially so given the convergence in several similar studies. Finally, we noted that behavioral changes were especially correlated with measurements of fiber intensity, not areal density. Because fiber intensity may be an index of neurotransmitter amount, rather than areal number of fibers, this measure may be the most appropriate to use in future studies of behavior.

\section{REFERENCES}

Antier, S. I. New hotplate tests to quantify antinociceptive and narcotic antagonist activities. European Journal of Pharmacology, 1974, 27, 1-4.

Bjorklund, A., Dunnett, S., Stenevi, U., \& Gage, F. H. Cross-species neural grafting in a rat model of Parkinson's disease. Nature, 1982, 298, 652-654.

Bjorklund, A., Segal, M., \& Stenevi, U. Functional reinnervation of rat hippocampus by locus coeruleus implants. Brain Research, 1979, 170, 409-426.

Bjorklund, A., \& STEnevi, U. Experimental reinnervation of the rat hippocampus by grafted ganglia. I. Axonal regeneration along the hippocampal fimbria. Brain Research, 1977, 138, 259-270.

Brady, J. V., \& Nauta, W. J. H. Subcortical mechanisms in emotional behavior: The duration of affective changes following septal and habenular lesions in the albino rat. Journal of Comparative and Physiological Psychology, 1955, 48, 412-420.

Chafetz, M. D. Recovery of function from septal damage and the growth of sympathohippocampal fibers. Unpublished doctoral dissertation, Texas Christian University, 1981.

Chafetz, M. D., Evans, S., \& Gage, F. H. Fluorescence measurement of lesion-induced fiber growth. II. Measurement of sympathohippocampal sprouting using a new microfluorometric method. Brain Research, 1982, 2A7, 217-226.

Chafetz, M. D., \& GaGe, F. H. Fluorescence measurement of lesion-induced fiber growth. I. A microfluorometric technique to measure density and intensity of varicosities and fibers. Brain Research, 1982, 247, 209-216.
Chafetz, M. D., \& Gage, F. H. Pineal and habenula innervation altered by septal lesions. Brain Research Bulletin, in press.

Chafetz, M. D., Thompson, R. G., Evans, S. H., \& Gage, F. H. Biochemical specificity of septal hyperreactivity: A behavioral discrimination. Behavioural Brain Research, 1981, 2, $409-420$.

Crutcher, K. A., Brothers, L., \& Davis, J. N. Sympathetic noradrenergic sprouting in response to central cholinergic denervation: A hippocampal study of neuronal sprouting in the rat hippocampal formation. Brain Research, 1981, 210, 115-128.

Crutcher, K. A., \& Collins, F. In vitro evidence for two distinct hippocampal growth factors: Basis of neuronal plasticity? Science, 1982, 217, 67-68.

Crutcher, K. A., \& Davis, J. N. Sympathetic noradrenergic sprouting in response to central cholinergic denervation. Trends in Neurosciences, 1981, 4, 70-72. (a)

Crutcher, K. A., \& Davis, J. N. Sympathohippocampal sprouting is directed by a target tropic factor. Brain Research, 1981, 204, 410-414. (b)

de la Torre, J. C., \& Suraeon, J. W. Histochemical fluorescence of tissue and brain monoamines: Results in 18 minutes using the sucrose-phosphate-glyoxylic acid (SPG) method. Neuroscience, 1976, 1, 451-453.

DiGiulio, A. M., Yang, H. Y. T., Lutold, B., Fratta, W., Hong, J., \& Costa, E. Characterization of enkephalin-like material extracted from sympathetic ganglia. Neuropharmacology, 1978, 17, 989-992.

Donovick, P. J., \& Wakeman, K. A. Open field luminance and "septal hyperemotionality." Animal Behavior, 1969, 17 186-190.

Evans, S., Neideffer, J. D., \& Gage, F. H. APL functions for interactive data analyses: Principal components analysis. Behavior Research Methods \& Instrumentation, 1981, 13, 657-666.

Gage, F. H., Armstrona, D. R., \& Thompson, R. G. Behavioral kinetics: $A$ method for deriving qualitative and quantitative changes in sensory responsiveness following septal nuclei damage. Physiology \& Behavior, 1980, 24, 479-484.

GAGE, F. H., \& Outon, D. S. Hippocampal influence on hyperreactivity induced by septal lesions. Brain Research, 1975, 98, 311-325.

GAGE, F. H., \& Outon, D. S. L-DOPA reduces hyperreactivity induced by septal lesions in rats. Behavioral Biology, 1976, 17, 213-218.

Gage, F. H., \& Springer, J. E. Behavioral assessment of norepinephrine and serotonin function and interaction in the hippocampal formation. Pharmacology, Biochemistry, and Behavior, 1981, 14, 201-212.

Gage, F. H., Thompson, R. G., \& Valdes, J. J. Endogenous norepinephrine and serotonin within the hippocampal formation during the development and recovery from septal hyperreactivity. Pharmacology, Biochemistry, and Behavior, 1978, 9, 359-367.

GAY, P. E. Activity levels and fixed interval performance in rats with septal lesions. Behavioral Biology, 1977, 20, 534-540.

Geyer, M. A., Dawsey, W. J., \& Mandel, A. J. Fading: A new cytofluorometric measure quantifying serotonin in the presence of catecholamines at the cellular level in brain. Journal of Pharmacology and Experimental Therapeutics, 1978, 207, 650-667.

Jones, G., Foote, S. L., Segal, M., \& Bloom, F. E. Locus coeruleus neurones in freely behaving rats exhibit pronounced alterations of firing rate during sensory stimulation and stages of the sleep-wake cycle. Society for Neurosciences Abstracts, $1978,4,856$.

Kimble, D. P., Anderson, S., BreMiller, R., \& Dannon, E. Hippocampal lesions, superior cervical ganglion removal, and behavior in rats. Physiology \& Behavior, 1979, 22, 461-466.

Kimble, D. P., BreMiller, R., \& Perez-Polo, J. R. Nerve growth factor applications fail to alter behavior of hippocampal lesioned rats. Physiology \& Behavior, 1979, 23, 653-657. 
Kohler, C., \& Srebro, S. Effects of lateral and medial septal lesions on exploratory behavior in the albino rat. Brain Research, 1980, 182, 423-440.

Kromer, L. F., Bjorklund, A., \& Stenevi, U. Innervation of embryonic hippocampal implants by regenerating axons of cholinergic septal neurons in the adult rat. Brain Research, 1980, 210, 153-171.

LEvine, M. S. Canonical analysis and factor comparison. Beverly Hills, Calif: Sage, 1977.

Loy, R., \& Milner, T. A. Sexual dimorphism in extent of axonal sprouting in rat hippocampus. Science, 1980, 208, 1282-1284.

Loy, R., Milner, T. A., \& Moore, R. Y. Sprouting of sympathetic axons in the hippocampal formation: Conditions necessary to elicit ingrowth. Experimental Neurology, 1980, 67, 399-411.

Loy, R., \& Moore, R. Y. Anomalous innervation of the hippocampal formation by peripheral sympathetic axons following mechanical injury. Experimental Neurology, 1977, 57, 645-650.

Milner, T. A., \& LoY, R. A delayed sprouting response to partial hippocampal deafferentation: Time course of sympathetic ingrowth following fimbrial lesions. Brain Research, 1980, 197, 391-396.

Moes, P., Graves, D., Kesslak, P., \& Gage, F. H. Behavioral function of sympathetic sprouting and its relation to lighting conditions and lighting cycles. Society for Neurosciences Abstracts, 1981, 7, 885 .

Morgan, W. W., \& Hansen, J. T. Time course of the disappearance of pineal noradrenaline following superior cervical ganglionectomy. Experimental Brain Research, 1978, 32, 429-434.

Nie, N. H., Hull, C. H., Jenkins, J. G., Steinbrenner, K., \& Bent, D. H. Statistical package for the social sciences (2nd ed.). New York: McGraw-Hill, 1975.

Nikolov, N. D. Synchronization of spontaneous activity of skeletal muscle, autonomic nerves, and brain structures in cats. Neirofiziologiya, 1976, 8, 146-151.
Perlow, M. J., Freed, W. J., Hoffer, B. J., Seiger, A., Olson, L., \& WYATT, R. J. Brain grafts reduce motor abnormalities produced by destruction of nigrostriatal dopamine system. Science, 1979, 204, 643-646.

Rosene, D. L., \& Van Hoesen, G. W. Hippocampal efferents reach widespread areas of cerebral cortex and amygdala in the rhesus monkey. Science, 1977, 198, 315-317.

SChNeIder, G. E. Early lesions of superior colliculus: Factors affecting the formation of abnormal retinal projections. Brain Behavior Evolution, 1973, 8, 73-109.

Schoenfeld, T. A., \& HAmilton, L. W. Secondary brain changes following lesions: A new paradigm for lesion experimentation. Physiology \& Behavior, 1977, 18, 951-967.

STENevi, U., \& BJorkLUND, A. Growth of vascular sympathetic axons into the hippocampus after lesions of the septohippocampal pathway: A pitfall in brain lesion studies. Neuroscience Letters, 1978, 7, 219-224.

Stenevi, U., Bjorklund, A., \& SvendgaARd, N. Transplantation of central and peripheral monoamine neurons to the adult rat brain. Techniques and conditions for survival. Brain $\mathbf{R e}$ search, 1976, 114, 1-20.

TURner, F. D., \& GAGE, F. H. A sensitive apparatus for the measurement of sensory reactivity in the rat. Physiology \& Behavior, in press.

Valdes, J. J., Cameron, W. R., Evans, S., \& Gage, F. H. Regional brain morphine injections selectively attenuate aspects of septal hyperreactivity: A multivariate assessment. Pharmacology, Biochemistry, and Behavior, 1980, 12, 563-572.

Wall, P. D., \& EgGer, M. D. Formation of new connexions in adult rat brains after partial deafferentation. Nature, 1971, 232, 542-545.

(Manuscript received October 4, 1982; revision accepted for publication December 9,1982 .) 